\title{
Using the Laser Scanning Technology in the Evaluation of a Building Located on Ion Neculce Street from Cluj-Napoca
}

\author{
Mircea Emil NAP ${ }^{1}$, Tudor SĂLĂGEAN ${ }^{2 *}$, Petre Iuliu DRAGOMIR ${ }^{1}$, Elemer-Emanuel ȘUBA ${ }^{1,2}$ \\ ${ }^{1}$ Faculty of Geodesy, Technical University of Civil Engineering, 122-124 Lacul Tei Blvd., $2^{\text {nd }}$ District, \\ 020396, Bucharest, Romania \\ ${ }^{2}$ Faculty of Horticulture. University of Agricultural Sciences and Veterinary Medicine Cluj-Napoca, 3-5 \\ Mănăștur St, Cluj-Napoca, Romania \\ * corresponding author: tudor.salagean@usamvcluj.ro
}

BulletinUASVM Horticulture 76(2) / 2019

Print ISSN 1843-5254, Electronic ISSN 1843-5394

DOI:10.15835/buasvmcn-hort: 2019.0039

\begin{abstract}
Laser scanning describes a method by which a surface is sampled or scanned using laser technology. The science of valuation has become more and more sophisticated as the development of society in general and of the economy in particular, in order to meet, eventually, complex information needs. The main idea of this project is to carry out scanning works in the framework of the evaluation report of a property. For this project, The Leica Scanstation C10 laser scanner was used and the following methods were applied for the scan operation: Backward Intersection Method, Deletion Method. For the valuation we used Market approach and Cost approach. The use of the laser scanner led to the expected results, namely the retrieval of an enormous volume of information collected from the field, of extremely high accuracy which subsequently helped to model a large number of details necessary to improve the evaluation process.
\end{abstract}

Keywords: appraisal, laser scanner, market value

\section{Introduction}

In a century dominated by information as the most important development resource, the science of evaluation is called upon to provide crucial information to the exponents of economic activity. Realistic and accurate estimates lead, among others, to the establishment and stabilization of loans and investments that promote a development of real estate in the sense imposed by the society. As decisions regarding the use of property as well as property rights depend on extensive and solid knowledge, evaluators make a substantial contribution to those who make such decisions.

This leads us to the idea of our study, namely to introduce terrestrial laser scanning in the real estate evaluation process.
The current laser scanning technology can be divided into two categories: static and dynamic. The advantages of using static method are given by the high accuracy and the relatively high density of points. In the case of dynamic laser scans, the scanner is mounted on a mobile platform. These techniques require additional positioning systems such as INS and GPS, which make them more complex and more expensive (Călin et al, 2015).

Appropriate estimation of the value of real estate properties and the competent analysis of all the aspects related to them are used to support decisions regarding the disposition and use of the properties.

Regarding to general information, the property is located in the Grigorescu district of Cluj- 


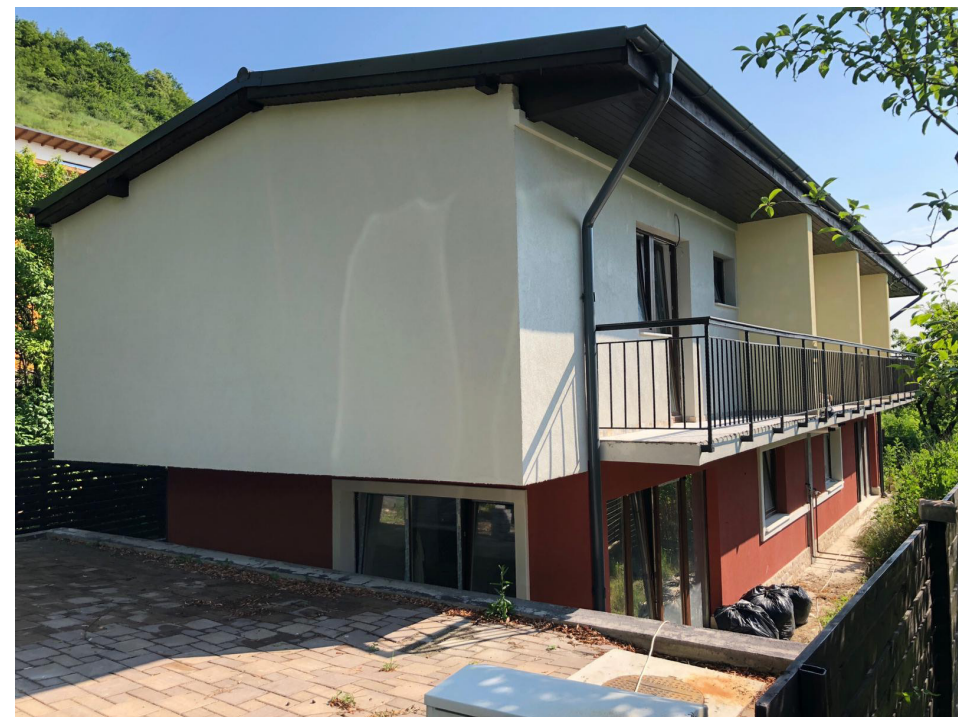

Figure 1. Photo of the property

Napoca, in a residential area close to the City Hall, with easy access to downtown.

The property has a regular shape, very close to a rectangle and a total measured area of 140 square meters, of which the construction covers 55 square meters.

\section{Materials and methods}

For this project the laser scanner Leica Scanstation C10 was used, which has a full view at $360^{\circ} \times 270^{\circ}$, high precision, long distance (300m @ $90 \%$ reflectivity) and high scan speed (50k pts/sec).

As regards data processing, specialized programs with licenses were used for this work, namely: Leica Cyclone 8.0 VIEWER \& VIEWER Pro Point Cloud Visualization, Global Mapper, AutoCAD and Microsoft Office 2016.

The first stage in the field works is the recognition of the land, where the area to be studied is located, at this stage the aim is to identify

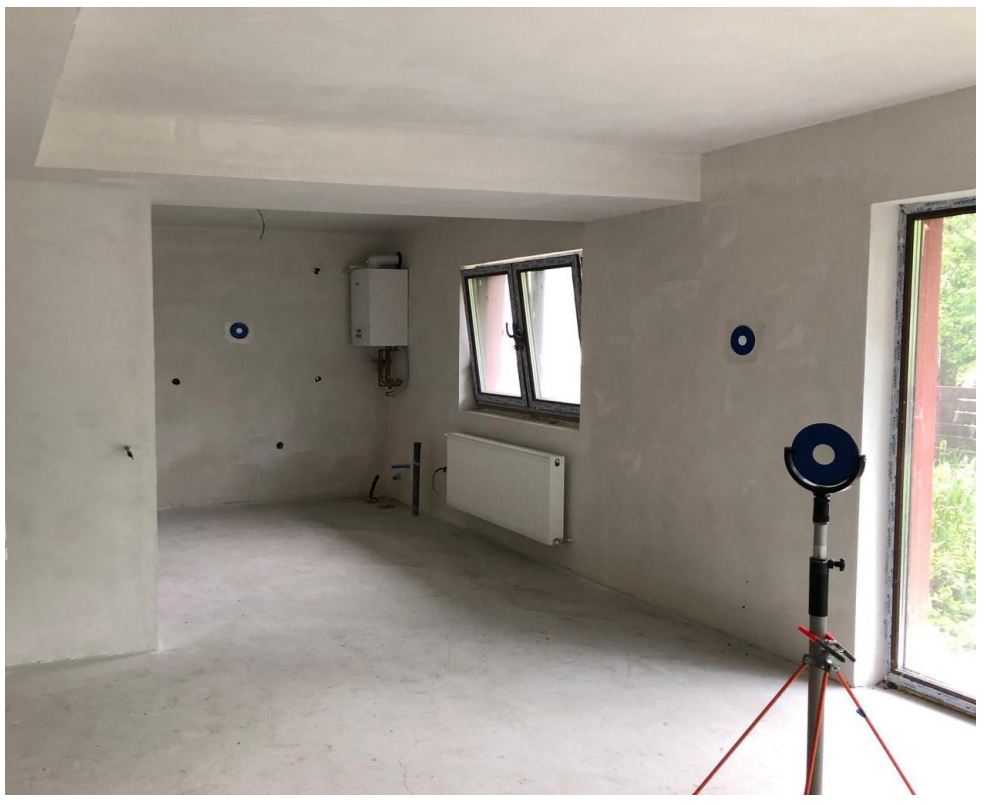

Figure 2. Setting the targets 
the following station points in order to carry out 3D scanning of the interior of the building.

For the coordinates of almost all stations, the Retrointersection Method was used, otherwise, the coordinates of the targets were determined by classical methods, the device having a special function for this operation in which it scans the target and finds its center, thus the accuracy being extremely high, this operation being presented in the image below:
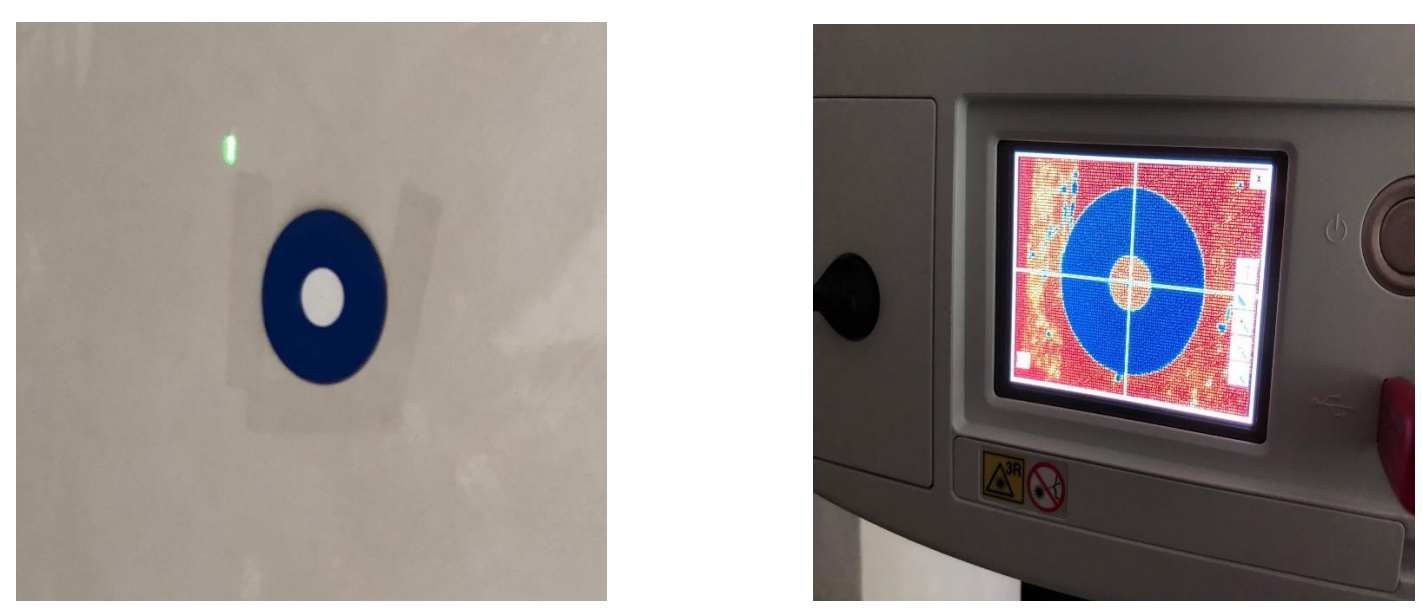

Figure 3. Determining the coordinates of a target

The actual scanning step begins, not before removing the handle of the device because the field of view is $270^{\circ}$ vertically, also in this stage being realized the photos for RGB code capture of each point in the point cloud. The device allows visualization of the scan from each station, being thus, different commands are available for scan research.

After the completion of the field works and the data retrieval, we went to the office works necessary to obtain the desired result, so in the Cyclone software we created a database where we imported those files. Accessing this newly created database we opened each scan at a time (Scan1 $\rightarrow$ Model Spaces $\rightarrow$ Open Temp Model Space View) and having this mode of view open, we performed the operation of allocating the RGB codes of each point in the point cloud (Edit Object $\rightarrow$ Appearence $\rightarrow$ Global Color Map).

Overlapping all 5 scans we get the gross result:

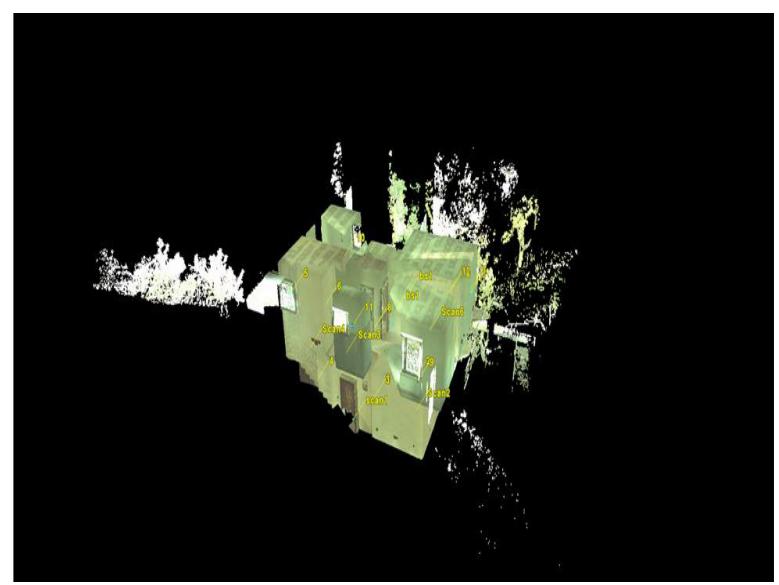

Figure 4. Overlapped scans - visualization according to the laser signal intensity/the RGB code taken from the images 


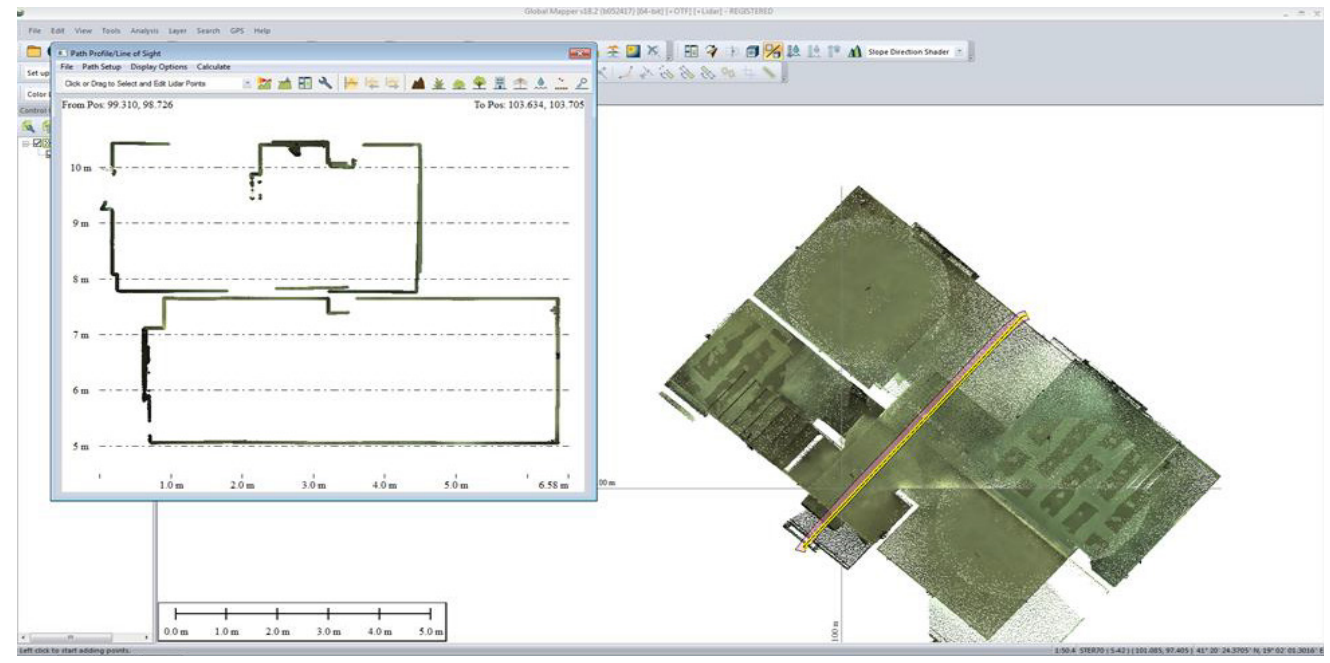

Figure 5. Vertical section by width

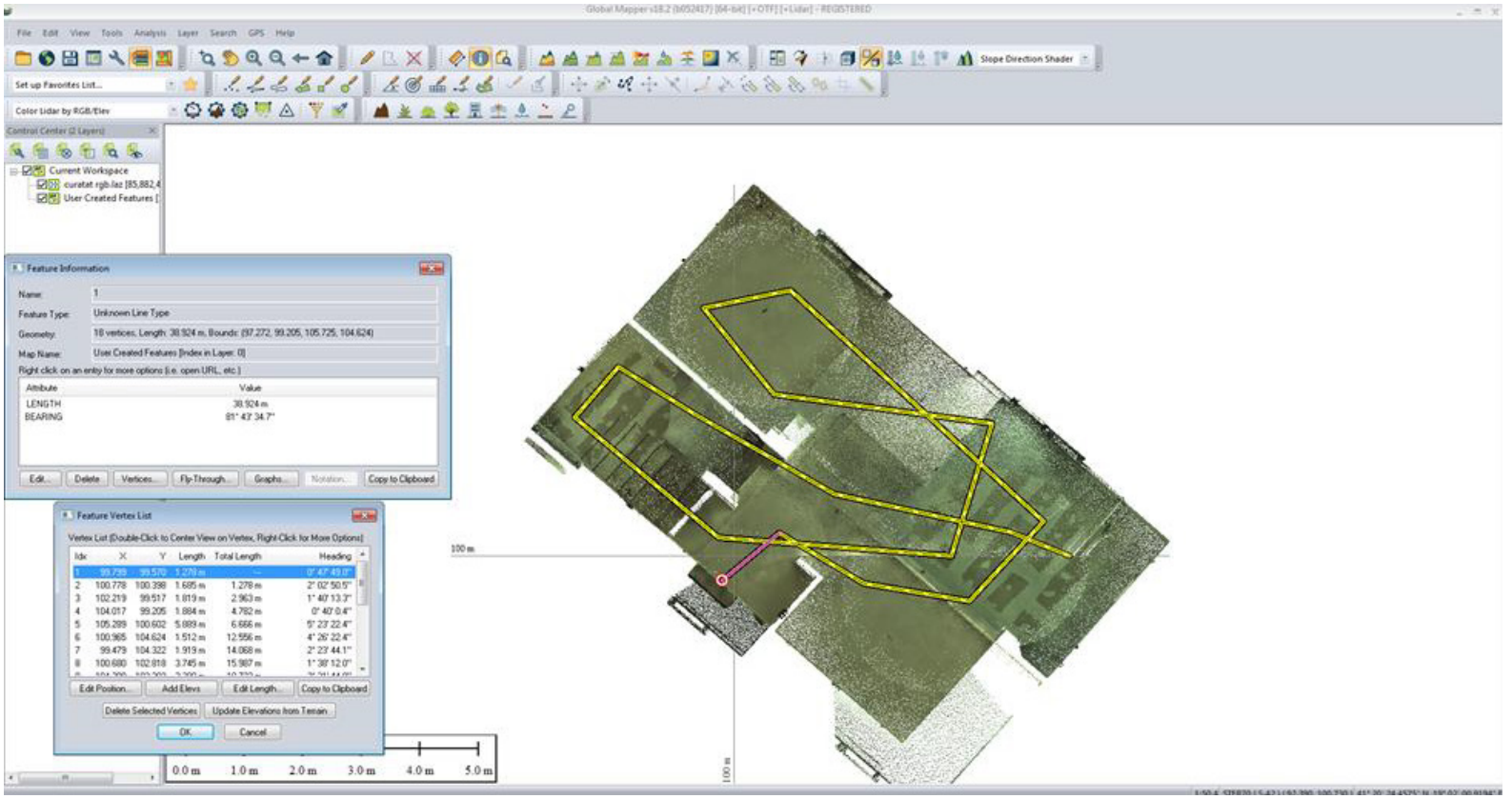

Figure 6. Creating the "Fly-through"

These scans thus present the so-called noise points, which need to be cleaned in order to proceed further in the process of processing, in this sense using a simple but very precise method, namely manual removal. (Călin et al, 2015)

Importing Cyclone processing results into Global Mapper, we had access to all the ways of processing of the software.

We used the function Path Profile $\rightarrow$ Line of sight to create a vertical profile (section) in length, and one in width (Fig. 5), hence taking the height for the ground floor and for the first floor, the total length and the width being otherwise easily visible.

Regarding the survey, using the same principle but another function, we have made horizontal profiles (sections) this time for both the ground floor and the first floor; these were realized on an established height set between 5.70-6.20 m for the ground floor, with the mention that the value of the height of the concrete floor from the ground floor was $5.05 \mathrm{~m}$, and for the fist floor the established height was set between 8.5-9.0 $\mathrm{m}$, the height of the slope being $7.8 \mathrm{~m}$. 
The last action carried out in the Global Mapper was the generation of „Fly Through” (Fig. 6). This is a 3D virtual tour of the entire interior of the building. For this it was necessary to create some vertices and to set them, firstly mentioning the field of vision and the position of the „camera” in the forward direction, then we needed to select the height of each vertex separately; we opted for the route to be executed at a height of $1 \mathrm{~m}$ above the slopes, so that at the ground floor the vertices had a height of $6.0 \mathrm{~m}$, the stairs climbed to 7.8 $\mathrm{m}$, the middle plate with a height of $6.8 \mathrm{~m}$, and upstairs were set at $8.8 \mathrm{~m}$.

For the real estate appraisal we used 2 classic approaches, as follows:

The Market Approach, in which the analysis of the prices of the comparable properties is applied according to the comparison criteria appropriate to the specific of the property. The similarities and differences between the characteristics of the comparable properties and those of the subject property were analyzed, and the necessary adjustments were made according to the comparison elements. Recommended comparison elements include, but are not limited to: ownership rights passed, financing conditions, conditions of sale, necessary expenses immediately after the purchase, the market conditions, the location, the physical characteristics, the economic characteristics, the use, the non-real estate components of the property. Selecting the conclusion on the value was determined by the comparable real estate property which was the closest physically, legally and economically to the subject real estate and the price at which the smallest adjustments were made. Following the application of the selected method, the market value of the analyzed property resulted. It was estimated at: 115,680 Euro (Market value real estate house + land). (ANEVAR, 2019; Șchiopu, 2019).

According to "GEV 630 Real Estate Valuation", the Cost approach represents the process of obtaining an indication on the value of the subject real estate by deducting from the new cost of the construction / constructions, the cumulative depreciation and adding to this result the estimated value of the land at the date of assessment. According to the results obtained by applying the specific methods of cost approach, both regarding the land and the building, it is deduced that the Value of the property without the developer's profit is 102,806 Euro. In this method, the profit of the developer must be estimated by the appraiser very carefully, so that it is within the limits practiced on the market at the time of the evaluation, in this sense carrying out detailed analyzes, and in some cases even consulting is required from some construction engineers or developers, so after consulting with three developers currently active in the real estate market in Cluj-Napoca, we concluded that the profit margin of a local developer at the time of assessment is between $10-20 \%$ / housing unit. After applying this correction, using the 15\% percentage in calculation, the market value of the assessed property was estimated at 118,226 Euro.

\section{Results and discussion}

Any evaluation report is prepared to answer a specific question and to deliver specific information requested to the authorized evaluator by the client.

Types of reports: an evaluation report is generally a written document, having one of the two forms of value reports, these being named Typical Report (form), respectively Explanatory Report (narrative).

The purpose of the appraisal, the complexity of the subject real estate and the users' requirements will determine the appropriate degree of detail and the appraisal report, so for this paper, we drafted an explanatory evaluation report.

An explanatory report presents the facts, techniques and methods of evaluation that the evaluator has applied in the analysis process in order to estimate the defined value or to formulate another conclusion, according to the client's requirements. This type of report reflects the evaluator's ability to interpret relevant information and select appropriate assessment methods and techniques to estimate a (clearly defined) type of value.

Therefore, after analyzing the results obtained through the 2 evaluation methods presented previously (market, cost) and the data and information that were the basis of them, (property documents, measuremants, 3D Scan) we reached a trading amount of 116000 Euro. 


\section{Conclusion}

After the completion of the operations carried out for the elaboration of the work, and considering the purpose of this project, we have deduced some important aspects that will be presented in the following lines.

So, taking them one by one in order to achieve them, the first thing we would like to point out is the large volume of data collected from the field with the help of the laser scanner, which is an important advantage, but the minus of this activity is represented by the long time of work, for scanning the interior of the property in question, taking about 7-8 hours to complete.

Moving on to data processing in the office, we found that the precision and the multitude of details that can be modeled, represent probably the greatest advantage of this method, although here we discuss the same lengthy period of execution. Of these details I mention the finding of distances and surfaces, based on the horizontal profiles (sections) and not only; the dimensions of the floors and the exact positioning of virtually any sought detail.

All these added a significant improvement to the evaluation process in terms of the accuracy of the data underlying the calculations and the final report.

As a recommendation, however, I would like to point out that the use of laser scans in real estate appraisal processes should most likely be imposed only when evaluating high value properties, and with outstanding architecture, such as houses considered historical monuments in the centers of many cities, the stadiums of teams that are the subject of large transactions etc.

We proposed this recommendation due to the high costs involved in this process, starting from the high prices of the tools and the processing software, to the price of the labor, in our country being very few people authorized to perform such works, the working time having consequently a big price.

\section{References}

1. ANEVAR (2017) - Evaluarea proprietăților imobiliare, IROVAL, București.

2. Călin M, Damian G, Popescu T, Manea R, Erghelegiu B, Sălăgean T (2015). 3D Modeling for Digital Preservation of Romanian Heritage Monuments, Agriculture and Agricultural Science Procedia, ISSN 2210-7843, 6: 421428.

3. Călin M, Erghelegiu B, Manea R, Sălăgean T (2015). Point Cloud Comparison of Rock Sculpture of Decebalus Measured in Different Athmosferic Conditions, 15th International Multidisciplinary Scientific Geoconference ( SGEM 2015), Albena Bulgaria, Informatics, Geoinformatics and Remote Sensing Conference Proceedings, ISSN 13142704, 2: 415-422.

4. Șchiopu C (2019). Costuri de reconstrucție/Costuri de înlocuire Clădiri rezidențiale, IROVAL, București.

5. Tutorial Leica Cyclone 8.0

6. Tutorial Global Mapper

7. https://www.laserscanningforum.com/forum/ viewtopic.php?t=604

8. https://leica-geosystems.com/products/laser-scanners/ software/leica-cyclone

9. https://www.rqa.ro/globalmapper/ 